\title{
$3^{6 x}$
}
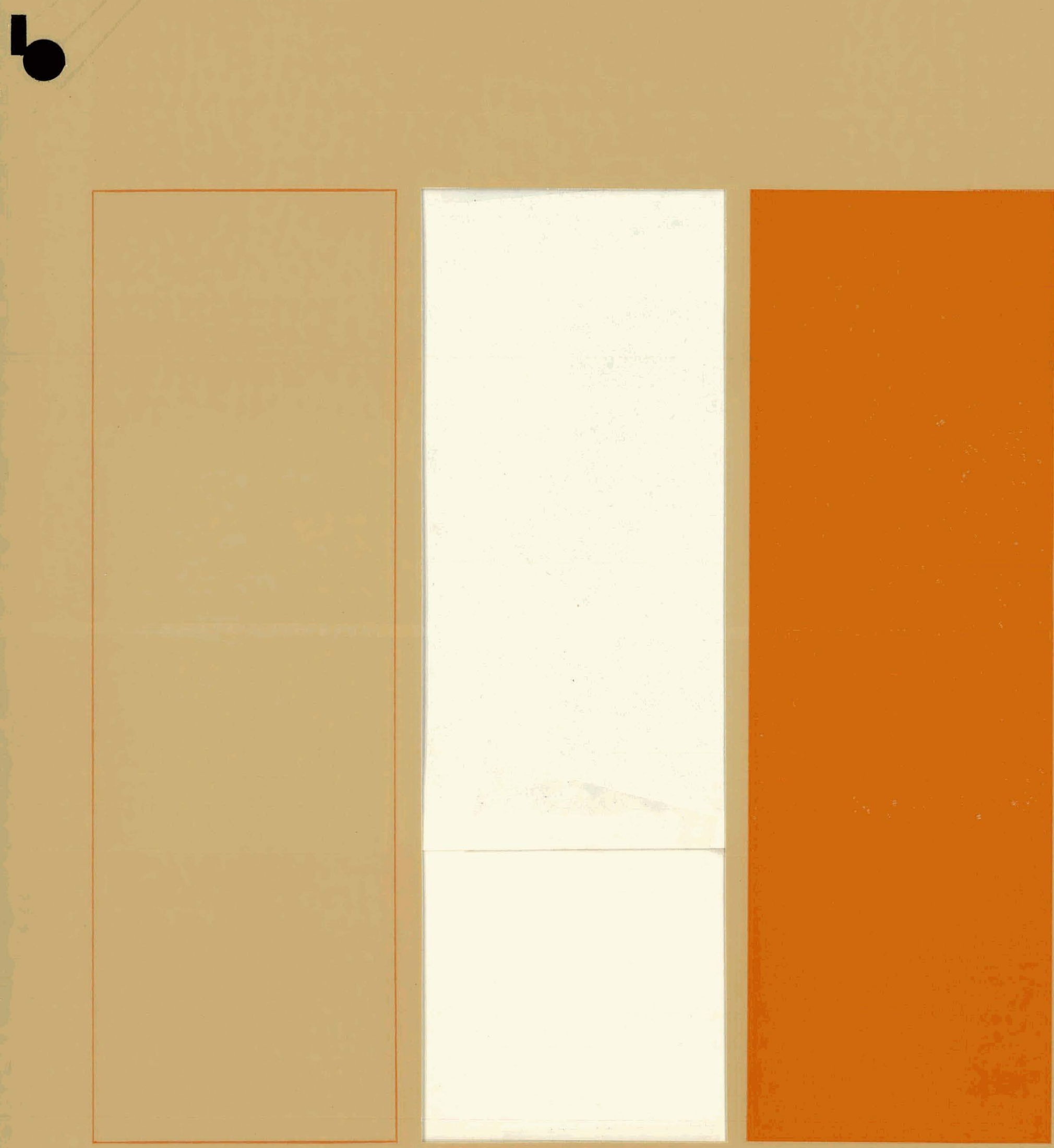

\section{Bendix Kansas City}

Division 


\section{DISCLAIMER}

This report was prepared as an account of work sponsored by an agency of the United States Government. Neither the United States Government nor any agency Thereof, nor any of their employees, makes any warranty, express or implied, or assumes any legal liability or responsibility for the accuracy, completeness, or usefulness of any information, apparatus, product, or process disclosed, or represents that its use would not infringe privately owned rights. Reference herein to any specific commercial product, process, or service by trade name, trademark, manufacturer, or otherwise does not necessarily constitute or imply its endorsement, recommendation, or favoring by the United States Government or any agency thereof. The views and opinions of authors expressed herein do not necessarily state or reflect those of the United States Government or any agency thereof. 


\section{DISCLAIMER}

Portions of this document may be illegible in electronic image products. Images are produced from the best available original document. 
SOLDER SPLATTER

CAUSED BY

OUTGASSING HOLES

IN PRINTED

WIRING BOARDS

BDX $-613-505$

May, 1971

Prepared by:

B. T. Lampe, D/814

M. I. Evans, D/821

C. L. Long, D/421, and

R. B. Snelt, D/821

This report was prepared as an account of work sponsored by the United States Government. Neither the United States nor the United States Atomic Energy Commission, nor any of their employees, nor any of their contractors, subcontractors, or their employees, makes any warranty, express or implied, or assumes any legal liability or responsibility for the accuracy, completeness or usefulness of any information, apparatus, product or process disclosed, or represents that its use would not infringe privately nwned rights. 
THIS PAGE

\section{WAS INTENTIONALLY LEFT BLANK}




\section{-n....}

\section{THE BENDIX CORPORATION}

KANSAS CITY DIVISION

KANSAS CITY, MISSOURI

A prime contractor for the Atomic Energy Commission

Contract Number AT(29-1)-613 USAEC

This report was prepared as an account of work sponsored by the United States Government. Neither the United States nor the United States Atomic Energy Commission, nor any of their employees, nor any of their contractors, subcontractors, or their employees, makes any warranty, express or implied, or assumes any legal liability or responsibility for the accuracy, completeness or usefulness of any information, apparatus, product or process disclosed, or represents that its use would not infringe privately owned rights. 
THIS PAGE

\section{WAS INTENTIONALLY LEFT BLANK}




\section{ABSTRACT}

A serious foreign material problem on the Lambda Assembly has been resolved by a change in the fabrication process for the printed wiring board. Foreign material in the form of solder splatter was found to originate from outgassing plated-through holes during soldering. Voids in the copper through-hole plating allowed molten solder to penetrate into the epoxy-glass base material of the board and decompose the epoxy. The gas evolved caused the solder joints to bubble and expel small solder balls over the surface of the board. The voids in the copper plating were found to be a direct result of the degradation of the as-drilled hole during one of the initial plating processes. Fluoboric acid in the plating bath attacked the exposed glass fibers along the sidewall of the drilled hole producing large cavities in the epoxy. Changing to a plating process which did not degrade the holes solved the problem. 
THIS PAGE

\section{WAS INTENTIONALLY LEFT BLANK}




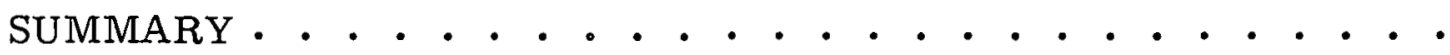

DISCUSSION • • • • • • • • • • • • • • • • • • • • • 13

SCOPE AND PURPOSE • • . . . . . . . . . . . . . . 13

Scope . . . . . . . . . . . . . . . . . . . 13

Purpose . . . . . . . . . . . . . . . . . 13

PRIOR WORK . . . . . . . . . . . . . . . . . . 13

ACTIVITY . . . . . . . . . . . . . . . . 19

Sampling . . . . . . . . . . . . . . . . 19

Microsections . . . . . . . . . . . . . . . . 19

Tests on FR-45 Base Laminate . . . . . . • . . . . 27

Effect of Drilling Speed and Rate on Hole Quality . . . . 30

Effect of Subsequent Fabrication Processes on Hole

Quality . . . . . . . . . . . . . . . . . 30

Solution to Problem. . . . . . . . . . . . . . . . 34

Rework of Outgassing Boards . . . . . . . . . . 37

ACCOMPLISHMENTS • • • . • . . • . • . • • • • 37

FUTURE WORK • • . • . . . . . • . • . . . . 38 
THIS PAGE

\section{WAS INTENTIONALLY LEFT BLANK}




\section{ILLUSTRATIONS}

Figure

Page

1 Printed Wiring Assembly (P-65156) . . . . . . . . .

15

2 Solder Splatter on Surface of Soldered Board (P-68079) . .

3 Cross-Section of Plated-Through Hole That Did Not Outgas $(\mathrm{P}-68117)$. . . . . . . . . . . . . . .

4 Cross-Section of Plated-Through Hole That Outgassed When Soldered $(\mathrm{P}-68117)$. . . . . . . . . . . . . . 23

5 Cross-Section of Outgassing Hole (P-68116) . . . . . . 25

6 SEM Photographs of Outgassing Holes (Polaroid) . . . . . 28

7 SEM Photographs of Good Hole (Polaroid) . • . . . . . . 29

8 SEM Photographs of AS-Drilled Hole (Polaroid) . . . . . . 32

9 SEM Photographs of Drilled Hole After Copper Fluoboric Plating (Polaroid) . . . . . . . . . . . . .

Cross-Sections of Holes From Boards Fabricated Using Copper Sulfate and Copper Cyanide Plating (P-70572). . . 
THIS PAGE

WAS INTENTIONALLY

LEFT BLANK 


\section{SUMMARY}

Foreign material problems on the Lambda were traced to outgassing plated-through holes in the printed wiring board. The outgassing was found to be caused by voids in the through-hole copper plating which allowed molten solder to penetrate into the epoxy-glass base material causing it to outgas. The outgassing from the epoxy caused the solder joint to bubble and expel molten solder over the surface of the board in the form of small solder balls.

Outgassing holes were found in large numbers on every nickel-clad Lambda board tested. Efforts to rework the outgassing boards were not successful. Vacuum baking, chemical cleaning, and solder leveling were found to be ineffective in reducing the amount of outgassing from the plated-through holes.

Voids in the copper through-hole plating were found at points where the bundles of glass fibers ran perpendicular to the sidewall of the hole. These voids were formed as a natural consequence of the copper plating following the rough contour of the drilled hole in the epoxy-glass base material. The rough hole was not caused by a poor drilling operation, but rather by the attack of the exposed glass fibers in the hole during the fluoborate copper plating of the board surface. Because the drilled holes are left unprotected during this process, the fluoboric acid in the plating bath attacks and dissolves the glass fibers. The resulting pits and voids in the sidewalls of the holes are not sealed off by subsequent copper plating. During soldering, molten solder penetrates into these voids and reacts with the epoxy causing it to outgas directly into the solder filled hole.

The outgassing problem on the Lambda boards was resolved by changing plating processes. A change from fluoborate copper to either sulfate cupper or cyanide coppcr prevents degradation of the drilled holes during plating of the board surface. Boards fabricated using either a copper cyanide or a copper sulphate plating process for the initial copper plate siiovied no evidence of outgassing from the holes. The plated-through holes in these buards had smooth, continuous copper plating with no voids.

During the experimental work on this problem, tests on the FR-45 (Formica) epoxy/glass base material showed large variations in the state of cure of the epoxy. These variations were not a contributing factor in the outgassing problem, however. A separate study of this cure problem was conducted jointly by the Materials Engineering departments of Bendix Kansas City and Sandia Laboratories, Albuquerque (SLA). A report, "Phase I Evaluation of FR 45 Clad Laminates, " is tentatively scheduled for release by G. Voida (SI.A) by May, 1971. 
THIS PAGE

\section{WAS INTENTIONALLY LEFT BLANK}




\section{DISCUSSION}

\section{SCOPE AND PURPOSE}

$\underline{\text { Scope }}$

Foreign material on high reliability electrical assemblies can be a serious production problem. One common type of foreign material is solder splatter found on the printed wiring board. Solder splatter can originate from a number of sources. Recently, outgassing from plated-through holes during soldering was found to cause solder splatter. Foreign material problems on the Lambda have been traced to outgassing holes.

The outgassing solder splatter problem appeared to be limited to the nickelclad printed wiring boards used in these assemblies. A typical Lambda assembly is shown in Figure 1. Figure 2 is a close up view of the surface of one of the boards after several of these holes had been soldered. The large number of small.solder balls on the surface of the board, some of which were found as far as four inches away from the solder joints, were produced by the outgassing holes.

Most of the solder balls are held in place by the solder flux residue and can be removed with a solvent. However, others adhere so tightly to the epoxy-glass laminate or tin-lead coated conductor paths that they cannot be removed by cleaning. These must be removed manually. The solder balls which become lodged beneath the body of a mounted component are almost totally inaccessible or detectable and often increase the required amount of rework. Outgassing holes can also cause low strength, marginal solder joints as a result of entrapped gas bubbles.

\section{Purpose}

An investigation was made to determine and eliminate the cause of outgassing from plated-through holes.

\section{PRIOR WORK}

Mr. P. A. Falke of the Electronics Products Engineering Department has made high-speed motion pictures of outgassing holes in Lambda printed wiring boards. The films, which show molten solder being expelled from a hole during soldering, substantiated the solder splatter problems caused by outgassing plated-through holes. 


\section{THIS PAGE}

\section{WAS INTENTIONALLY \\ LEFT BLANK}




\section{7}

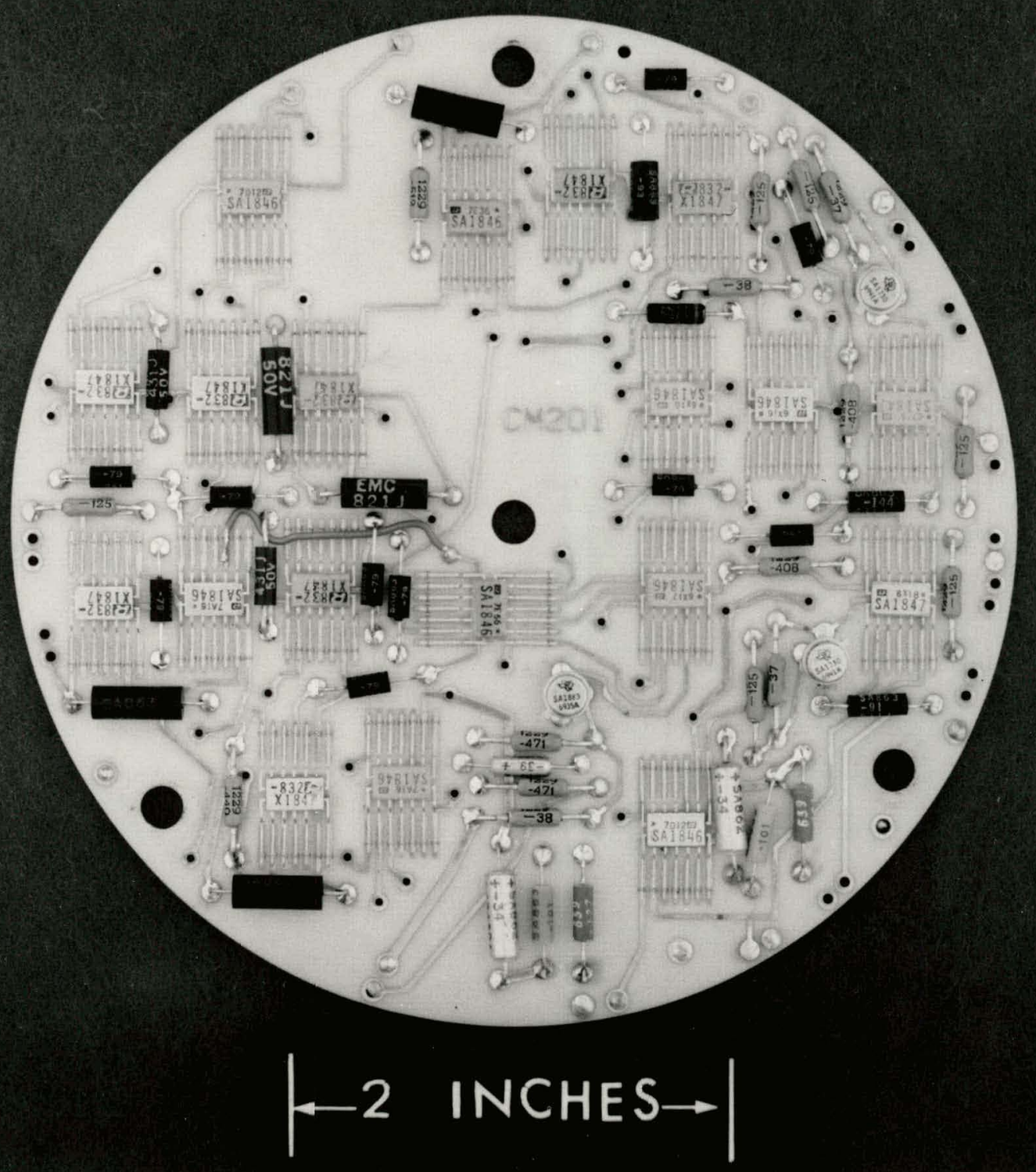

Figure 1. Printed Wiring Assembly 
UNCLASSIFIED

Pr 31 I 4 AUG 301971

9 
THIS PAGE

\section{WAS INTENTIONALLY LEFT BLANK}



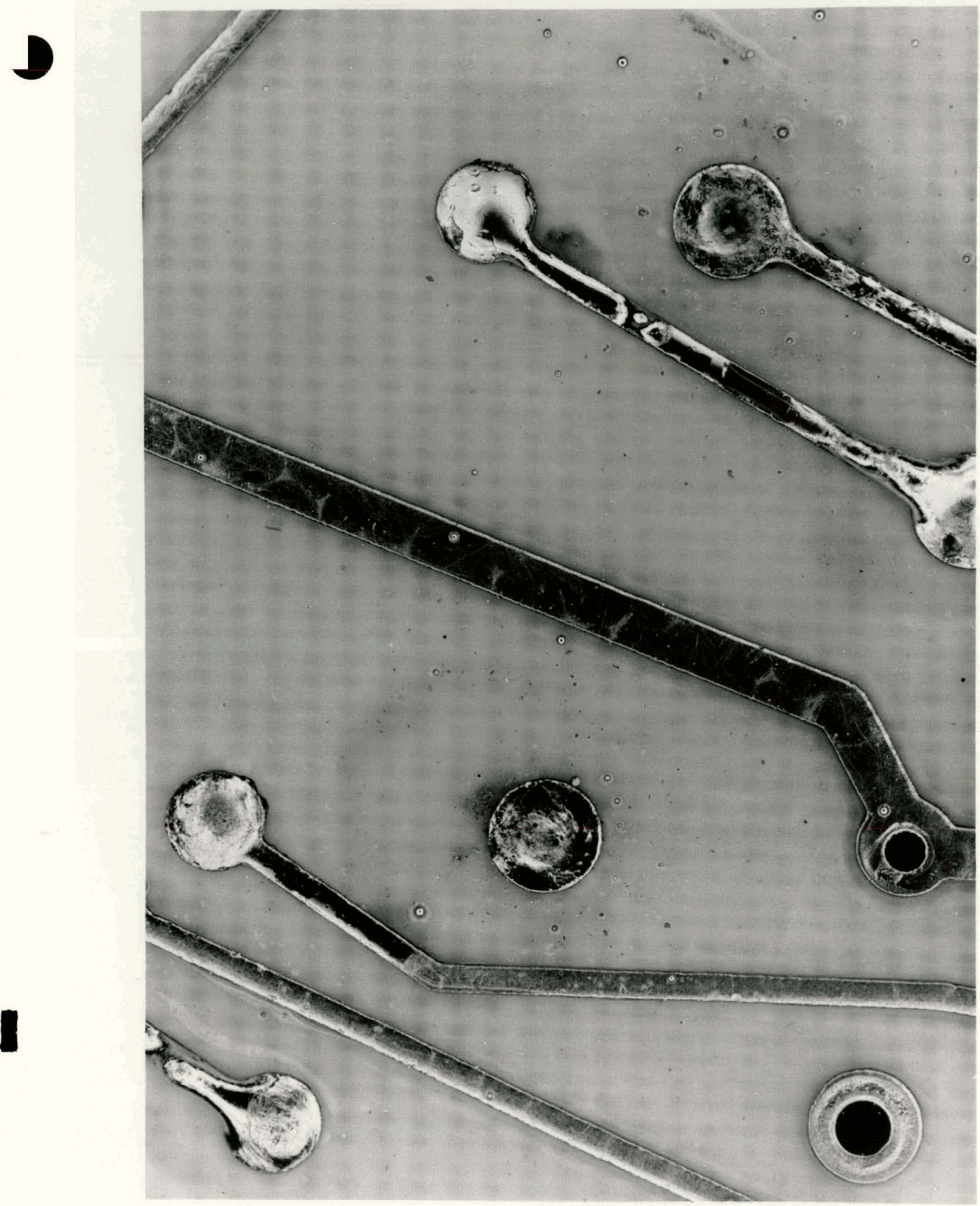

Figure 2. Solder Splatter on Surface of Soldered Board 
UNCLASSIFIED

P\& 31 \5 AUG 301971 
THIS PAGE

\section{WAS INTENTIONALLY LEFT BLANK}




\section{ACTIVITY}

The outgassing problem appeared to be confined to boards made from one type of epoxy-glass laminate--the nickel-clad FR-45 (Formica) heatresistant and flame-retardant material containing aluminum oxide and antimony trioxide fillers.

$\underline{\text { Sampling }}$

A large sampling was made of all in-house Lambda printed wiring boards of this type. The test for outgassing consisted of soldering a number of holes on each board with a 30-watt soldering iron. Almost every hole in these boards outgassed sufficiently to cause solder splatter on the surface of the board. The only Lambda nickel-clad boards that did not exhibit outgassing were from a very old lot of unknown origin. Comparable copperclad boards were also tested and did not exhibit any significant outgassing.

Microsections

Representative holes from both good and bad (outgassing) boards were cross-sectioned to permit a comparison of hole quality. Completed boards of both types were used. The holes were filled with solder prior to sectioning.

Figure 3 shows a typical microsection of a plated-through hole that did not outgas when soldered. Figure 4 shows a microsection of a typical outgassing hole. The difference between the good hole and outgassing hole is readily apparent. The copper plating on the sidewall of the good hole is smooth and continuous as compared to the rough plating on the sidewall of the outgassing hole. Cracks or voids in the copper plating are visible at numerous locations along the sidewall.

Photomicrographs of other outgassing holes are shown in Figure 5. The top left photomicrograph in Figure 5 shows a void extending into the epoxyglass base material and a gas bubble emerging from it. The top right photomicrograph in Figure 5 shows solder which has flowed into one of these cavities. The bottom photomicrographs in the transverse microsections of outgassing holes shown in Figure 5 illustrate the depth that molten solder (white area) penetrates into the epoxy-glass (black area). Solder is visible in the epoxy-glass beyond the copper jacket indicating that the solder has wicked up from below or down frum above the plane of the cross-section.

Text continued on page 27 . 
THIS PAGE

\section{WAS INTENTIONALLY LEFT BLANK}




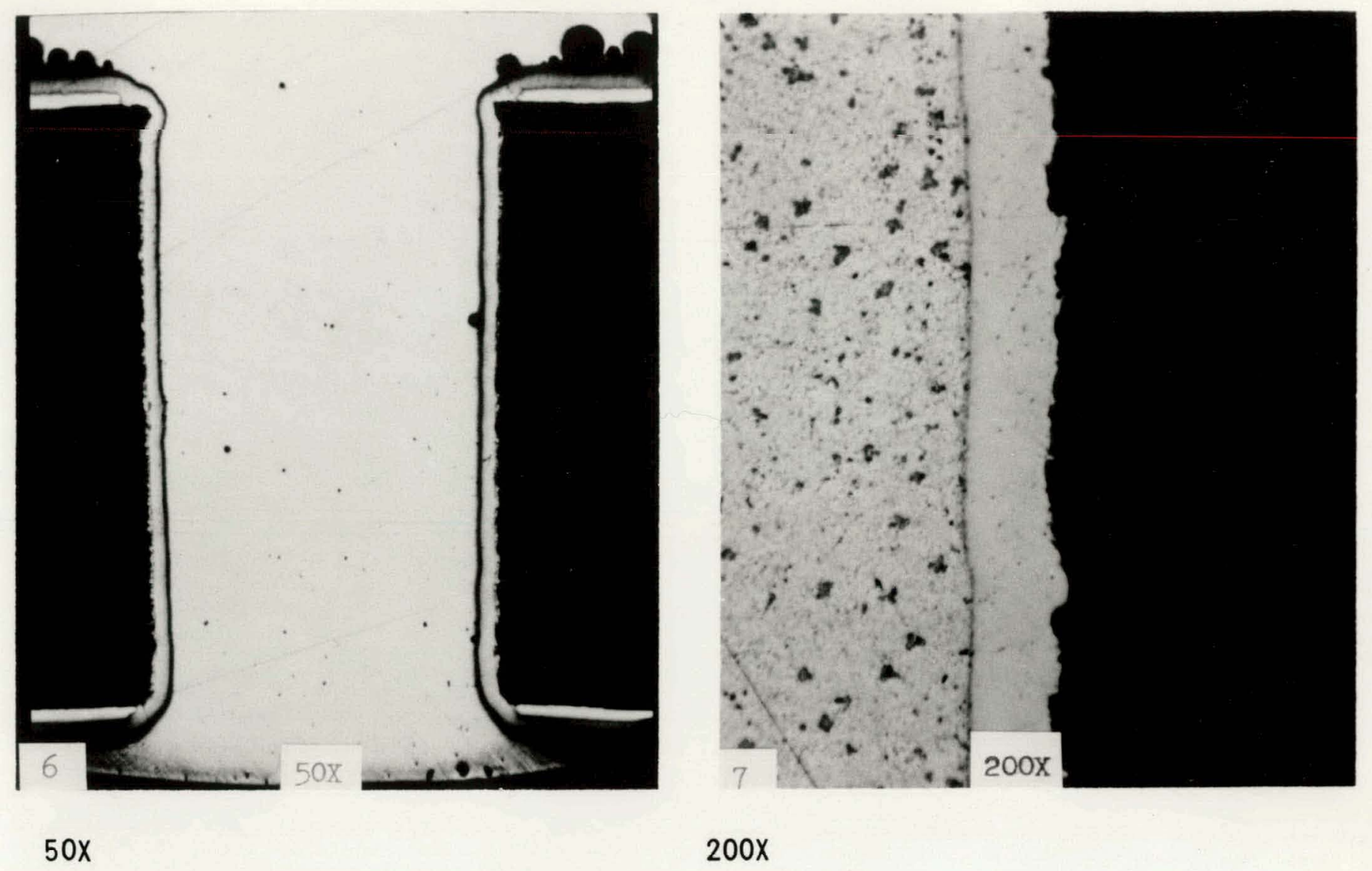

Figure 3. Cross-Section of Plated-Through Hole That Did Not Outgas 
UNCLASSIFIED
P73 136 AUG 301971

$d$ 


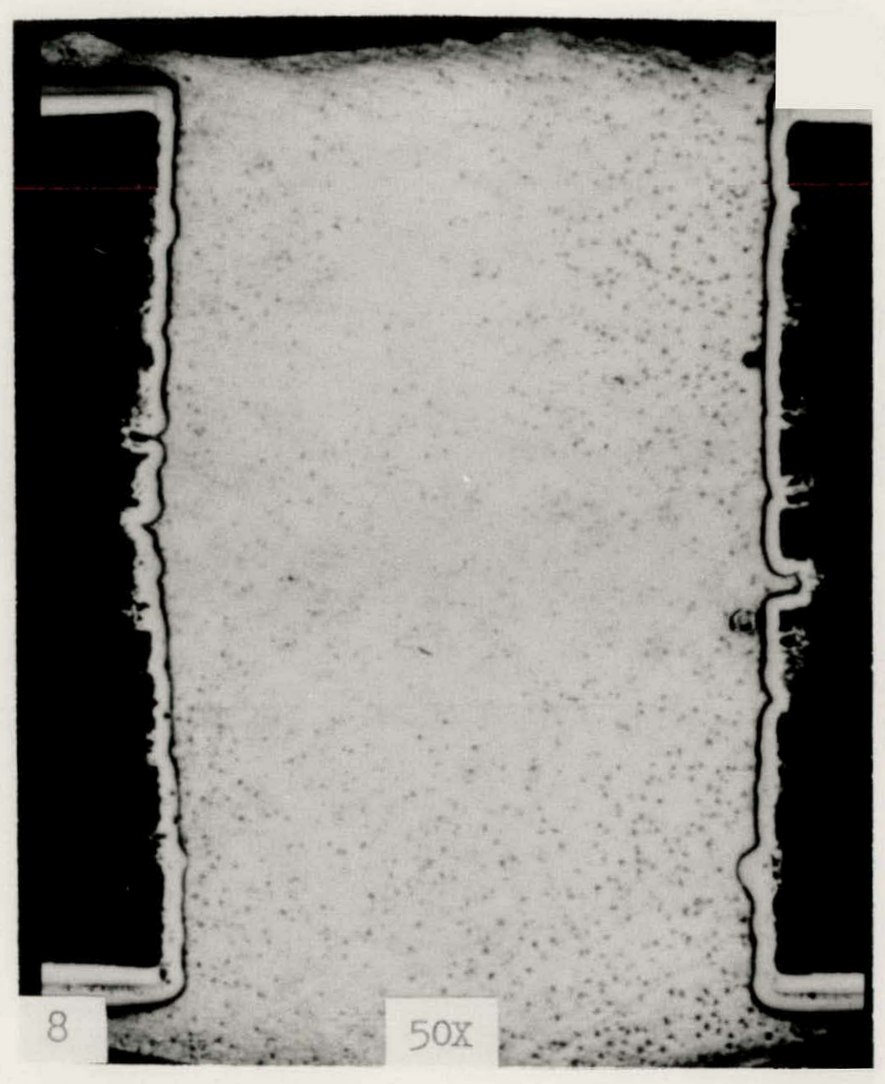

$50 x$

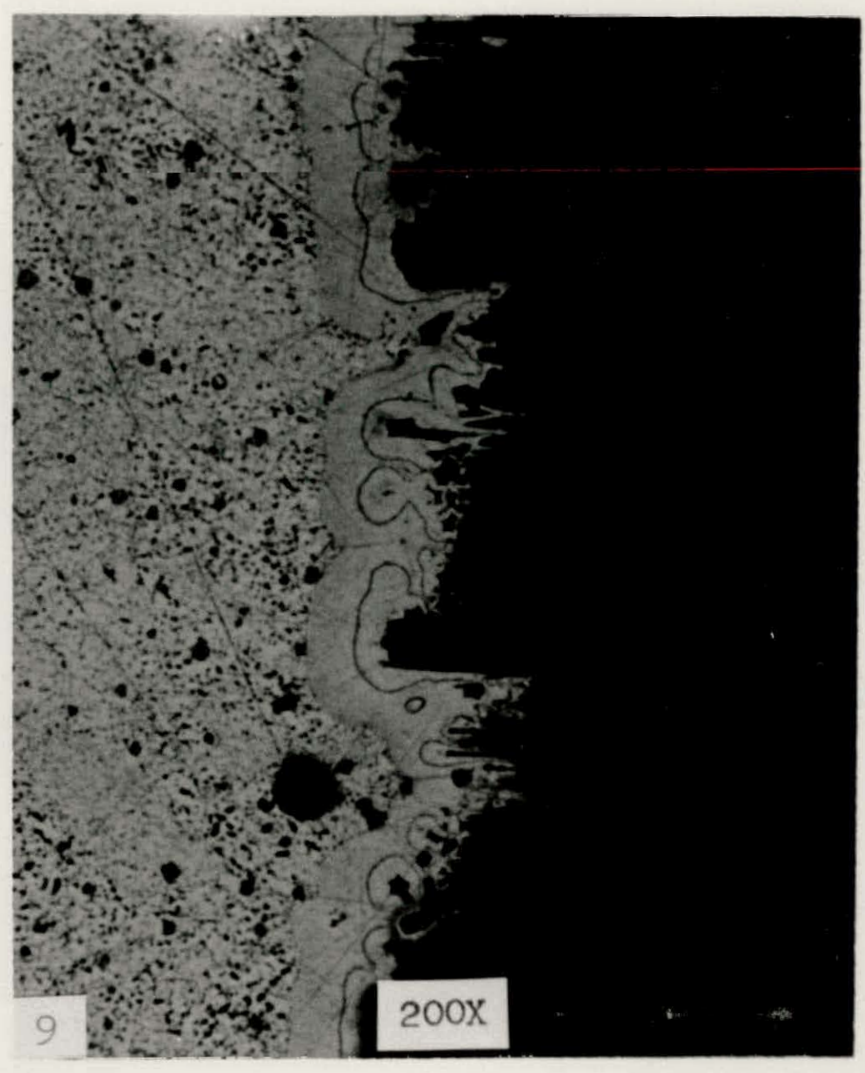

$200 x$

Figure 4. Cross-Section of Plated-Through Hole That Outgassed When Soldered 
UNCLASSIFIED

P7 31 3 9 AUG 301971 

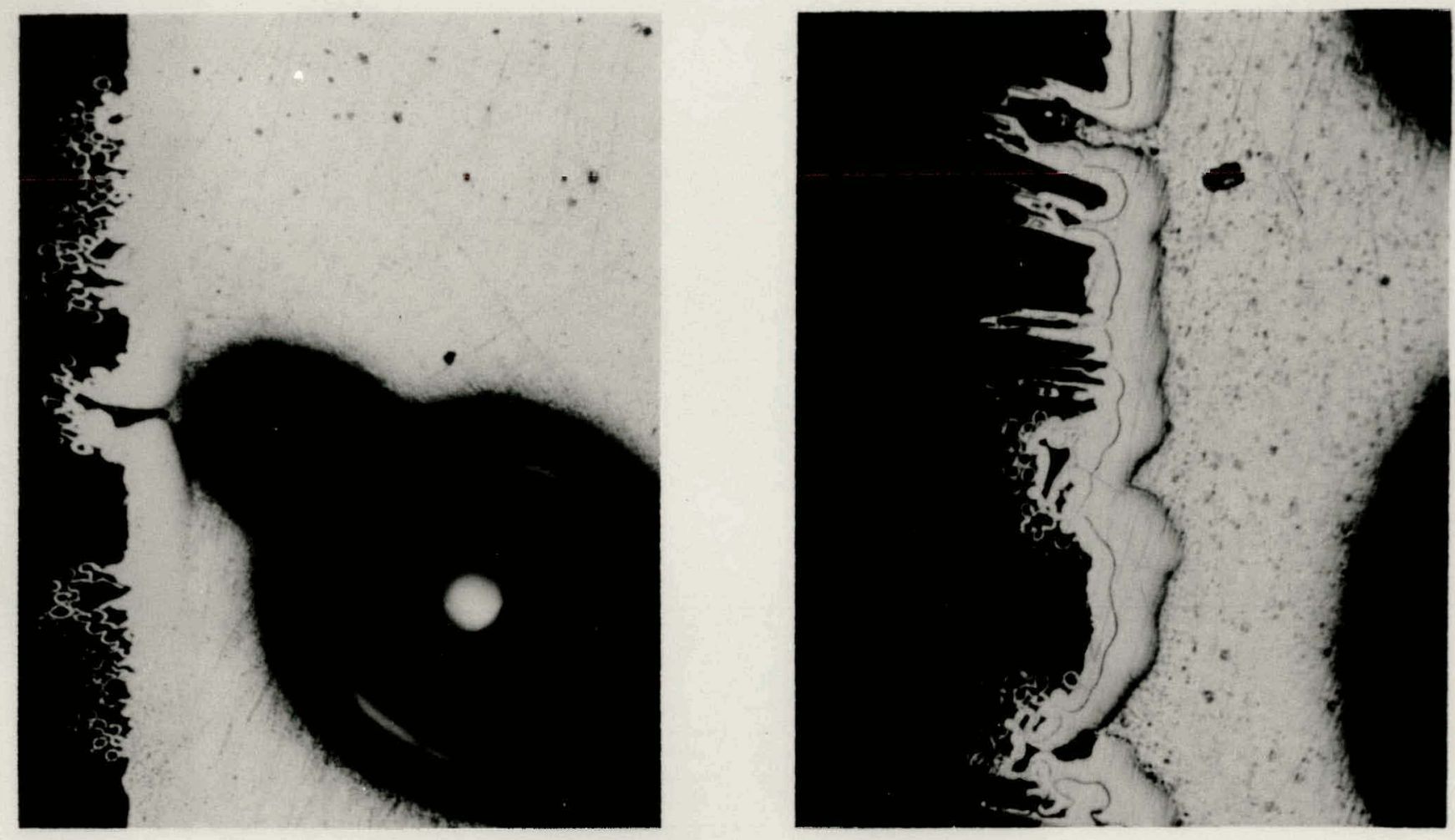

$180 x$

LONGITUDINAL CROSS-SECTION

$200 x$

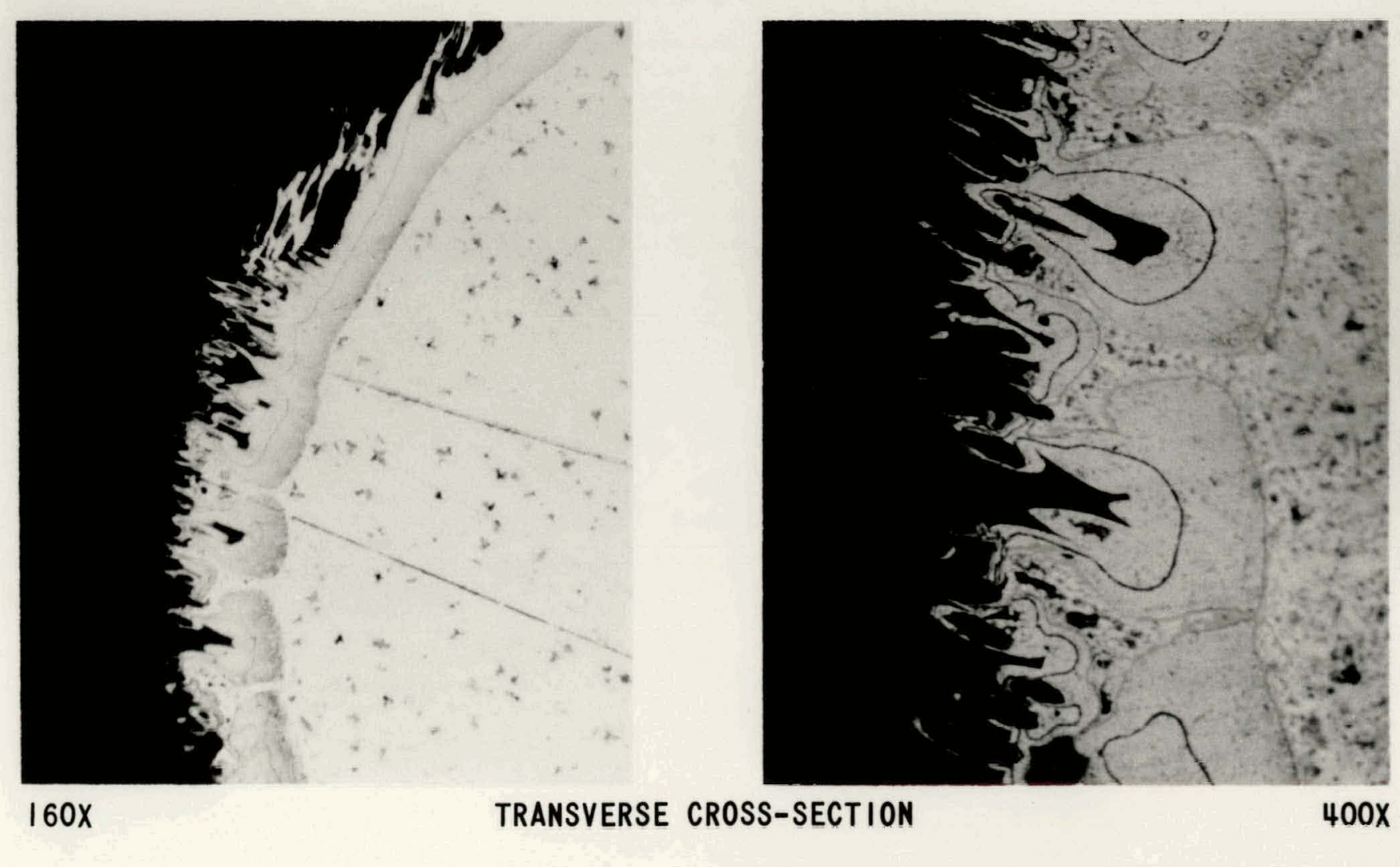

Figure 5. Cross-Section of Outgassing Hole 


\section{UNCLASSIFIED \\ P7 3 I 3 8 AUG 301971}

9 
It was apparent from the photomicrographs that outgassing was a direct result of cracks or holes in the copper through-hole plating. Even the good boards could be made to outgas by drilling a small hole in the sidewall of a plated-through hole. The cracks in the copper plating allow molten solder to penetrate into the epoxy-glass base material. The heat from the molten solder decomposes the epoxy causing it to outgas. A continuous copper plate in the hole, as shown in Figure 4, prevents the solder from reaching and decomposing the epoxy. In addition, any gas given off by the epoxy during the soldering operation is prevented from reaching the molten solder in the hole by the continuous copper jacket.

The difference in hole quality between good boards and outgassing boards is further illustrated by the scanning electron micrographs (SEM) taken of the holes with the copper jacket (plating) removed. SEM photos were taken of both the epoxy-glass surface and the surface of the copper jacket. The holes were dissected by grinding down about half way through the hole and removing the remaining copper with a pair of tweezers.

The SEM photographs in Figure 6 show the surface topography of a typical outgassing hole to be markedly different from that of the good hole shown in the SEM photographs in Figure 7. The sidewall of the good hole is smooth by comparison to the very rough sidewall of the outgassing hole. At points where the bundles of glass fibers run perpendicular to the sidewall of the outgassing hole, the fibers are loose with no epoxy around them. At high magnification (top right photograph of Figure 6) the fibers resemble the end of a broom. The roughness of the hole in the epoxy-glass is reflected by the texture of the copper jacket shown in the bottom photographs of Figure 6 . Shown highly magnified at the bottom right of Figure 6 are the tube-like structures produced by the copper plating which encapsulated the individual glass fibers. The lengths of the copper tubes are an indication of how far the copper plating extended into the epoxy-glass base material.

The voids in the copper through-hole plating of the outgassing boards appear to be a consequence of the plating around the rough sidewall of the drilled holes in the epoxy-glass. Nonoutgassing boards have smooth holes in the epoxy-glass and continuous copper plating in the holes.

Tests on FR-45 Base Laminate

When some of the outgassing printed wiring boards were noted to exhibit a somewhat textured or measled appearance, the FR-45 (Formica) base laminate became suspect. The so-called good boards did not have this appearance. It was thought that a high glass content or an over-cured epoxy might cause drilling problems and result in a condition similar to inai seen in tho photomicrographs. It was also observed that the base laminate from the bad boards outgassed to a considerably greater extent when placed in a hot oil bath than did the laminate from good boards. 

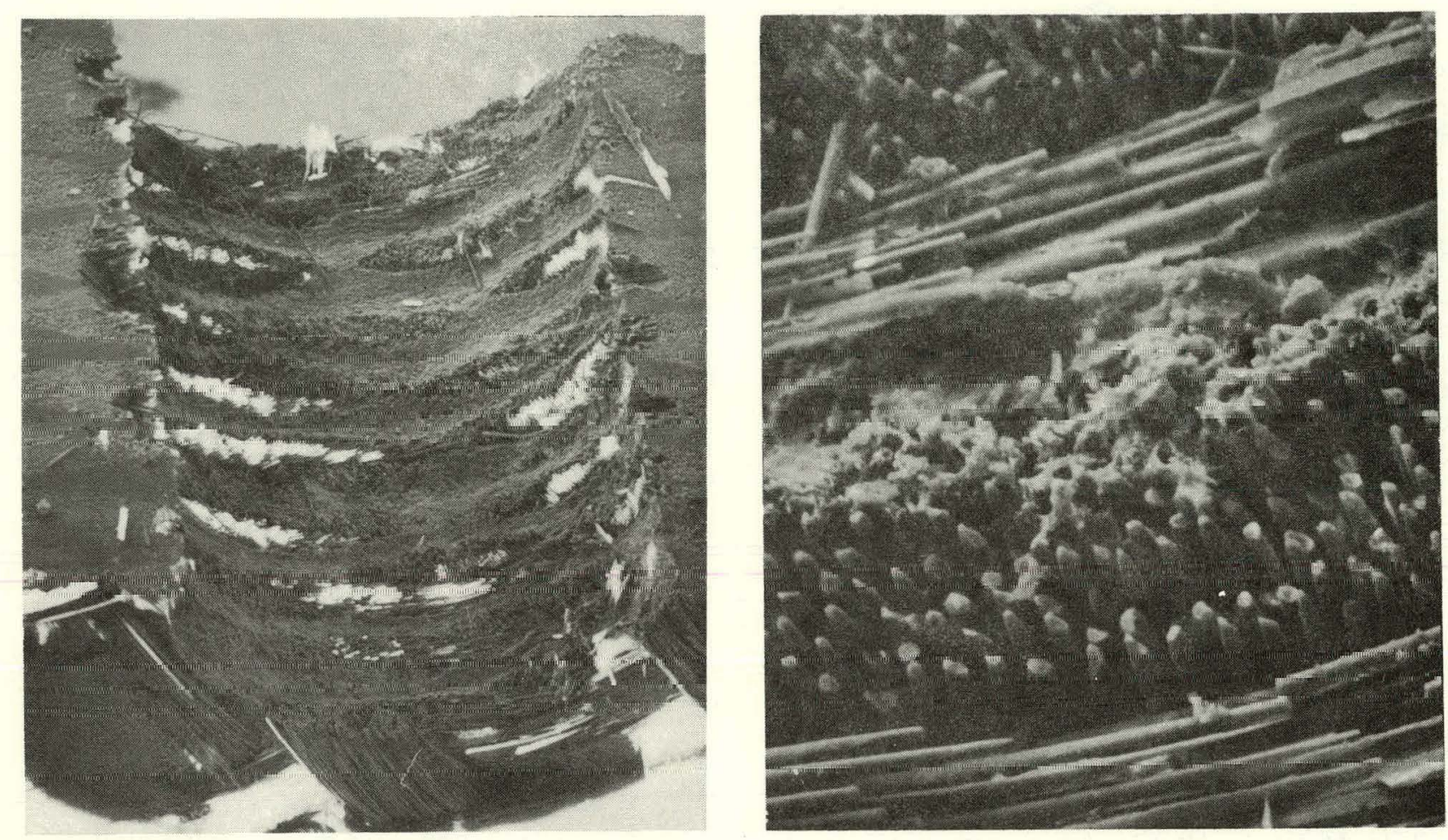

$50 x$

SURFACE OF EPOXY-GLASS WITH COPPER PLATE REMOVED

$400 x$
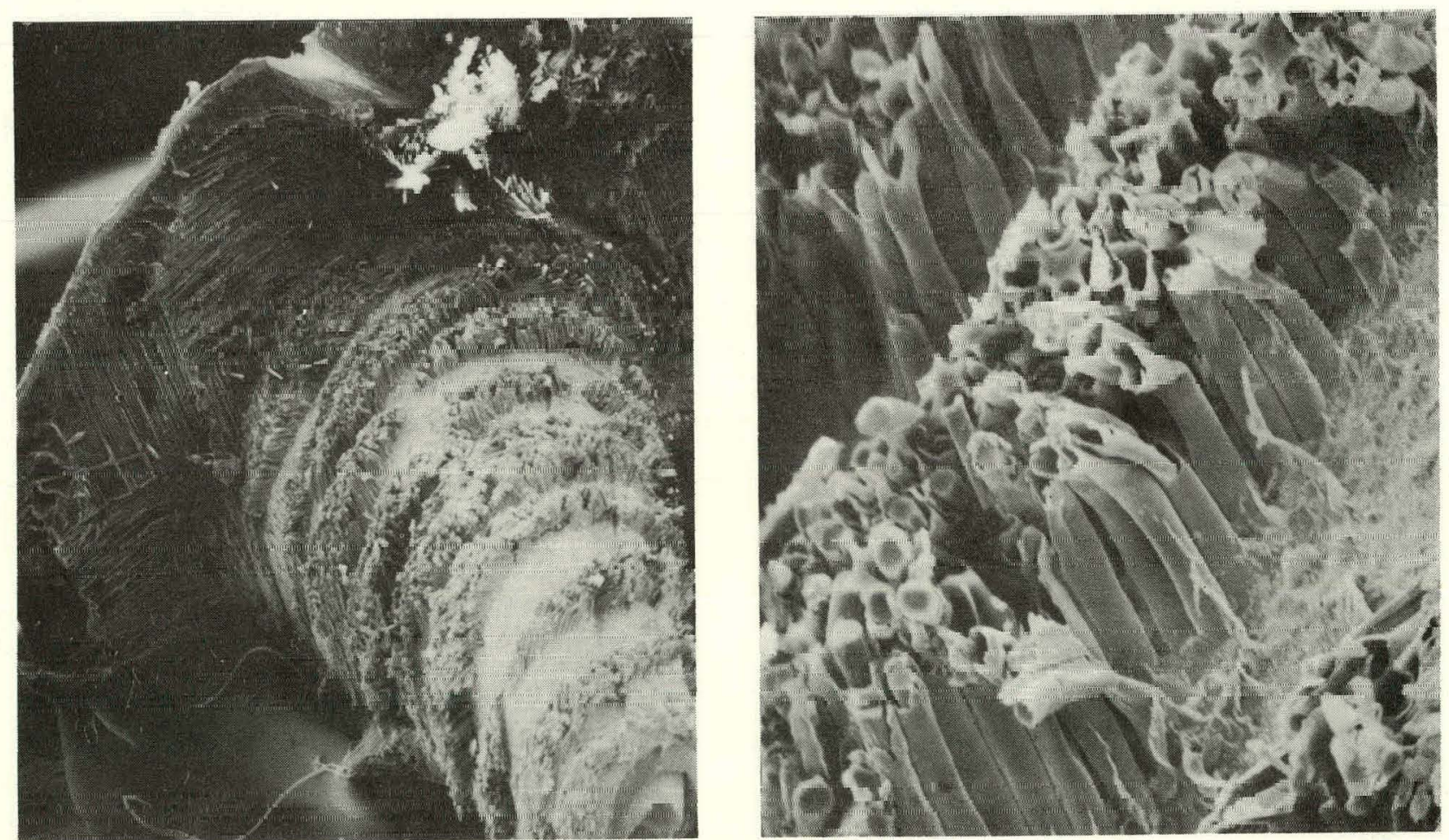

$50 x$

SURFACE OF COPPER PLATE REMOVED FROM HOLE

$400 x$

Figure 6. SEM Photographs of Outgassing Hole 

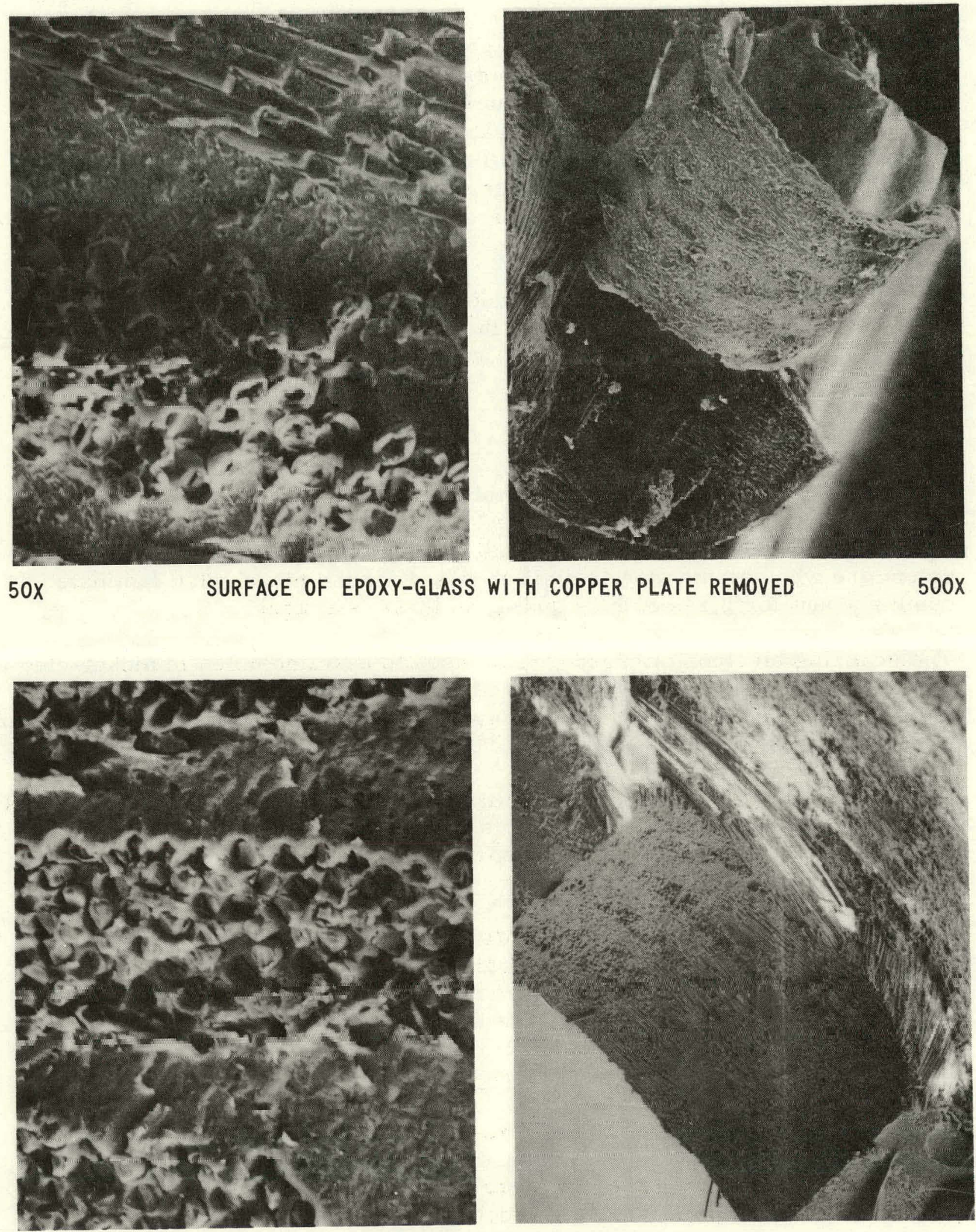

$50 x$

SURFACE OF COPPER PLATE

$500 x$

Figure 7. SEM Photographs of Good Hole 
Samples of the epoxy-glass laminate were analyzed for glass content and epoxy cure. The samples ranged from as-received material to samples taken from completed printed wiring boards. The glass content of the laminate was determined by burning off the resin from weighed samples. The state of epoxy cure was determined using a thermomechanical analyzer. This instrument measures the penetration depth of a weighted probe into the sample with temperature. From the data generated by this instrument, the softening temperature and glass transition temperature of the epoxy resin can be determined. The two parameters can be used as indicators of the state of cure of the epoxy.

The results from these tests showed no correlation between glass content and degree of cure of the epoxy with the incidence of outgassing holes. The glass content did not vary much from sample to sample, but the degree of cure varied considerably.

\section{Effect of Drill Speed and Rate on Hole Quality}

The nickel-clad Lambda boards are fabricated using a much slower drilling speed than is used for similar copper-clad boards. Slower drill speeds are required to minimize burrs in the nickel foil. A study was made to determine whether the slower drilling speed for the nickel-clad laminate could account for the poor hole quality in these boards.

The scanning electron microscope was used to examine holes in nickel-clad FR-45 laminate drilled at various speeds and feed rates. Three different drilling speeds and feed rates were investigated: 40,000 rpm (45 inches/min), 23, $000 \mathrm{rpm}$ (45 inches/min), and 15,000 rpm (35 inches/min).

The highest speed is the standard drilling and feed rate for copper clad FR-45 type laminate. The second speed is the standard drilling parameter for nickel-clad laminate. The slowest speed was chosen to determine how a lower feed rate affects hole quality.

No significant difference could be found in the quality of holes drilled at the different speeds and feed rates. All three drilling processes produced smooth holes in the epoxy/glass; it was therefore concluded that drilling was not the cause of the outgassing problem.

Effect of Subsequent Fabrication Processes on Hole Quality

Since the as-drilled holes in the nickel-clad laminate looked good, it was apparent that the holes were being degraded at some point in the board fabrication process. The holes were examined after each step in the fabrication process for possible degradation. The following is a brief listing of the various process steps involved in fabricating the Lambda nickel-clad board. 
1. Drill holes.

2. Vapor blast holes and surface.

3. Woods nickel strike and copper plate (surface only).

4. Pumice clean (surface only).

5. Apply photo resist and expose.

6. Develop resist paths.

7. Etch nickel circuit.

8. Strip photo resist.

9. Electroless copper plate (50 millionths in holes).

10. Copper electroplate (1/2 $\mathrm{mil}$ in holes).

11. Pumice clean.

12. Photo resist.

13. Copper electroplate (1 $\mathrm{mil}$ in holes).

14. Tin-lead electroplate

15. Strip photo resist and etch.

Boards with holes drilled at two different speeds and feed rates $(23,000$ and $15,000 \mathrm{rpm}$ ) were followed throughout the process. As mentioned previously, the as-drilled holes looked good. SEM photographs of a typical as-drilled hole are shown in Figure 8. No hole degradation was observed after vapor blasting. However, after the Woods nickel strike and copper plating process, SEM examination of the holes revealed that the exposed glass fibers had been attacked. At points where the glass fibers were perpendicular to the sidewall of the drilled hole, they had been eaten away producing large voids or cavities in the epoxy. The SEM photographs in Figure 9 show the degradation that occurred during this process.

The Woods nickel strike and copper plate process involves activating the nickel surface of the board with a Woods nickel strike followed by copper plating of the surface with about $1 / 2 \mathrm{mil}$ of copper from a fluoborate copper bath. The holes, which are not plated during this process, are exposed to the plating bath for about 50 minutes. 


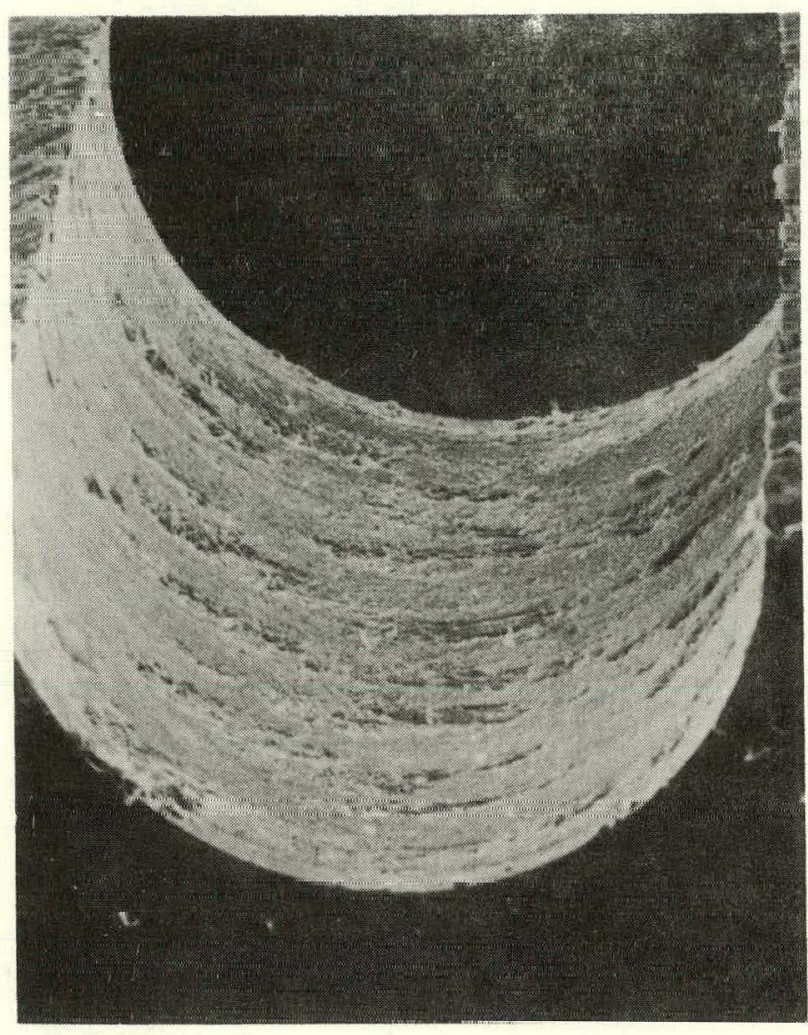

$55 x$

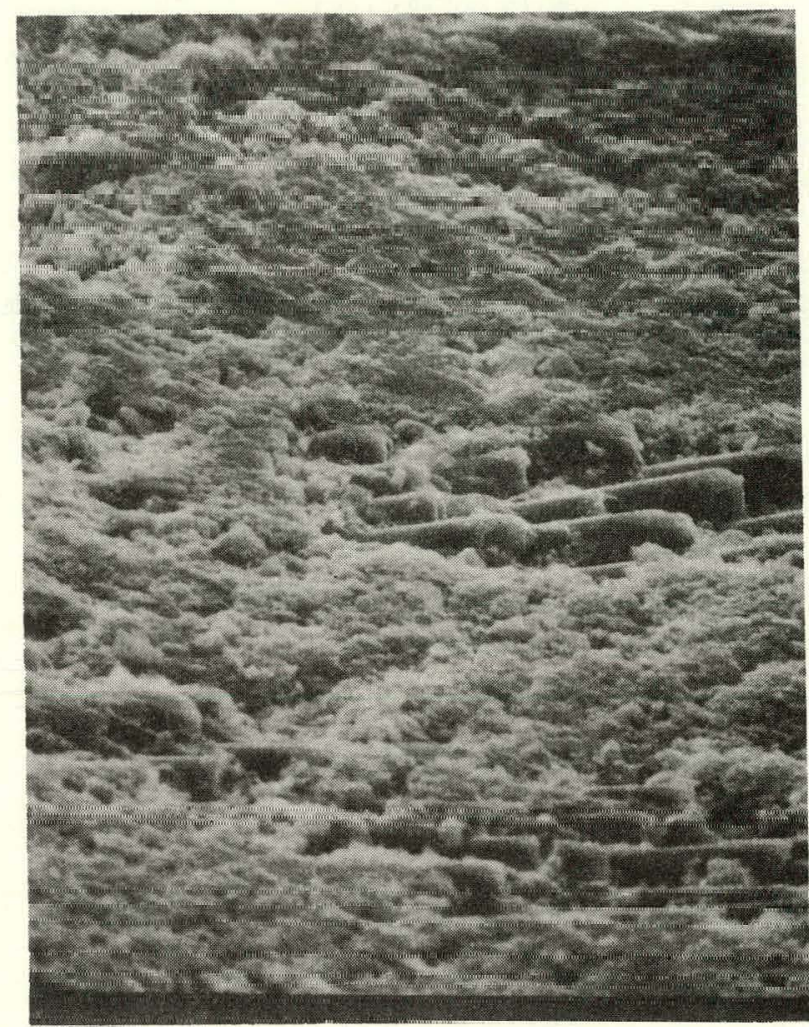

$500 x$

Figure 8. SEM Photographs of As-Drilled Hole 


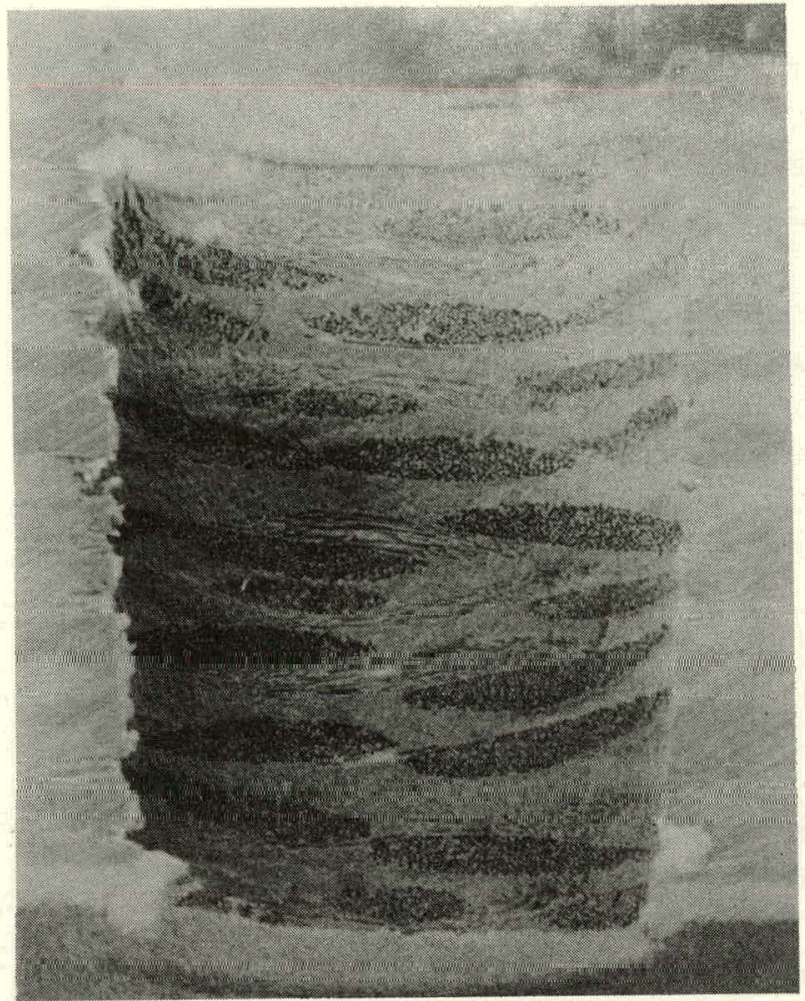

$50 x$

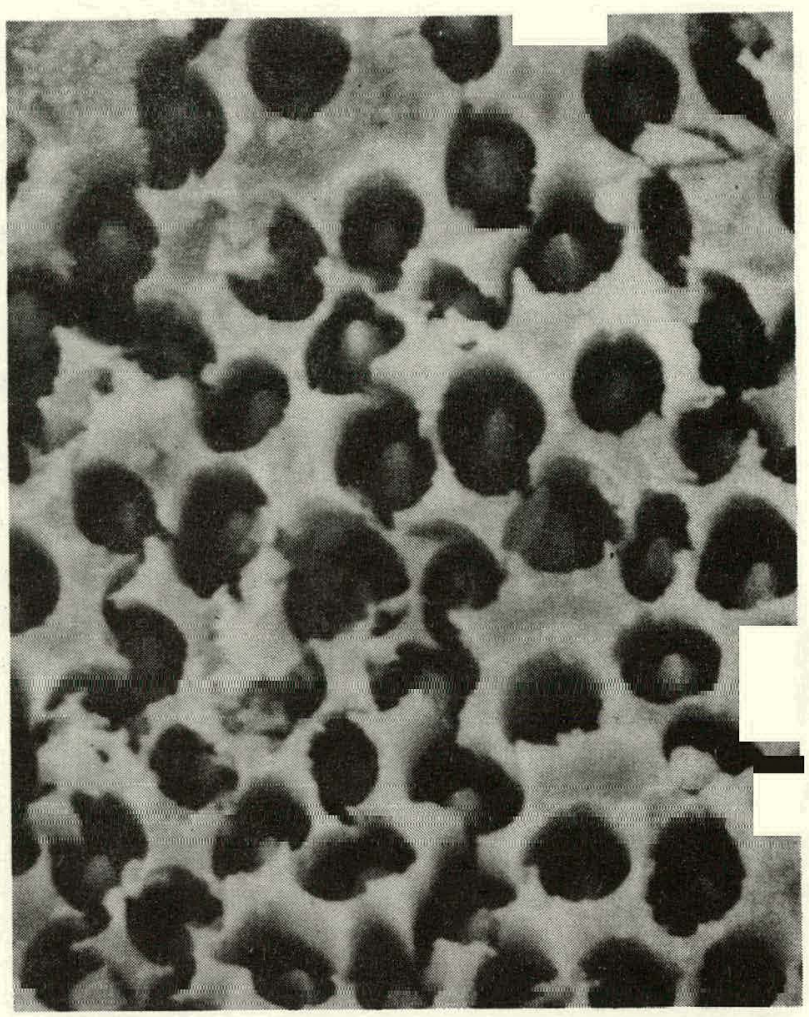

$1200 x$

Figure 9. SEM Photographs of Drilled Hole After Copper Fluoboric Plating (Polaroid) 
The fluoboric acid in the plating bath attacks the exposed glass fibers in the holes producing the condition shown in Figure 9. In some areas, the ends of the fibers can be seen by focusing down into the cavities. The rounded ends indicated that glass fibers had been dissolved rather than broken.

For each fiber attacked and dissolved by the fluoboric acid, a cavity is produced which extends into the epoxy a considerable distance. Later in the fabrication process, the holes are plated with electroless copper (a high throwing power bath) which plates into the cavities and encapsulates the remaining portion of the glass fibers, making both the fiber and the wall of the cavity conductive. The electroless copper plate is followed by two standard copper electroplates to build up the copper thickness in the hole to about $1.5 \mathrm{mils}$. The electroplated copper bath has much less throwing power than the electroless copper and will not plate into the cavities very far. The copper tends to build up at edges of the cavity producing the voids or cracks in the copper through-hole plating, as shown in the microsections. Sometimes the heavy electroplated copper will bridge over and seal off the cavity. However, at every place where the cavity is not sealed off, molten solder can penetrate into the epoxy during soldering and cause outgassing.

The holes were examined further after each processing step. No further hole degradation was observed.

\section{Solution to Problem}

Several alternative solutions were considered. To prevent exposure of the drilled holes to the fluoboric acid, it was proposed that the holes be drilled after fluoboric copper plating. A change to a different type of copper plating bath such as cyanide copper or sulfate copper was also suggested. The second solution, which was preferred, was evaluated by fabricating a number of boards using both cyanide copper and sulfate copper plating in place of the fluoborate copper. The holes in the boards were examined after each step in the fabrication process for possible degradation. No noticeable hole degradation was observed after any processing step. Holes from these boards were microsectioned after completion of the fabrication process. The quality of plated-through holes from both of the other copper plating baths was excellent with continuous copper through the hole and no voids or cracks. Typical microsections from these boards are shown in Figure 10. Soldering to the boards produced no outgassing whatsoever. 

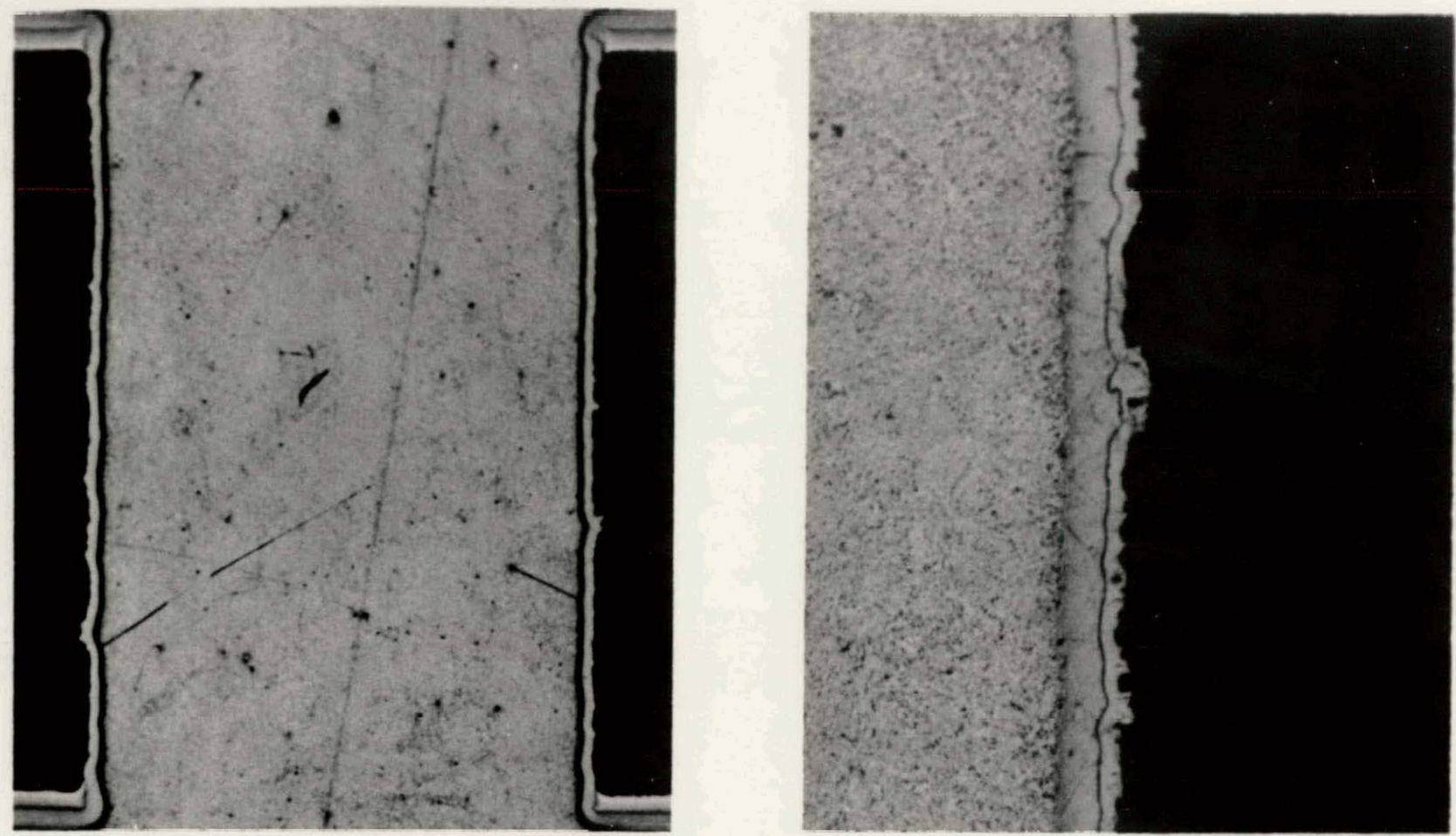

$50 x$

COPPER SULFATE PLATING

$200 x$
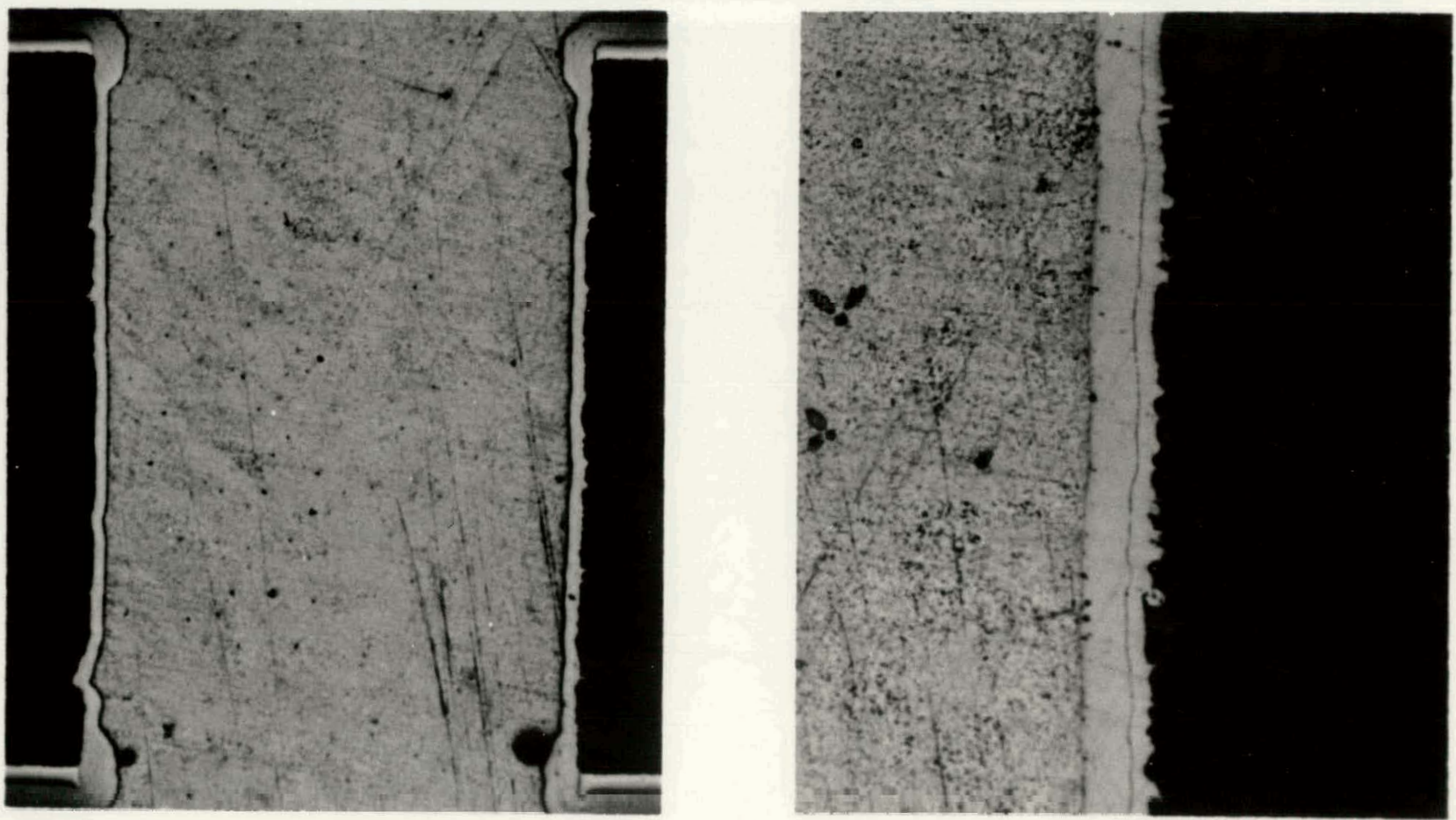

$50 x$

COPPER CYANIDE PLATING

$200 x$

Figure 10. Cross-Sections of Holes From Boards Fabricated Using Copper Sulfate and Copper Cyanide Plating 
UNCLASSIFIED

Pr 3137 AUG 301971

$d$ 
THIS PAGE

\section{WAS INTENTIONALLY LEFT BLANK}


A change was made to the Lambda board fabrication process to incorporate copper sulfate plating after the Woods nickel strike instead of the fluoborate copper. The incorporation of this change should eliminate the outgassing-solder splatter problem on the Lambda printed wiring boards.

$\underline{\text { Rework of Outgassing Boards }}$

A number of rework procedures were evaluated in an effort to reduce or eliminate the problem of outgassing holes on existing boards. Some of these are listed below.

- Chemical cleaning

- Baking at $200^{\circ} \mathrm{F}$ for 3 hours

- Solder leveling

- Vacuum baking at $200^{\circ} \mathrm{F}$ and $325^{\circ} \mathrm{F}$ for 2 hours

- Repeated peanut oil fusing

- Hot tin-lead dip at $500^{\circ} \mathrm{F}$

- Soldering with short and long dwell times using 550 to $750^{\circ} \mathrm{F}$ soldering irons.

None of the above significantly reduced the amount of outgassing from the holes. Some even compounded the problem. Soldering with the shortest possible dwell time on the solder joint minimizes the amount of solder splatter, but does not guarantee a solder joint that is free of gas bubbles.

\section{ACCOMPLISHMENTS}

As a result of this project, a major source of foreign material on the Lambda printed wiring board assemblies has been eliminated. Foreign material in the form of solder splatter was found to originate from outgassing plated-through holes in the printed wiring board. The cause of the outgassing was traced to one of the copper plating processes used to fabricate the board. Fluoboric acid in the plating bath was found to attack the exposed glass fibers in the drilled holes producing large voids or cavities along the sidewall of the holes. Since many of these cavities were not filled or sealed off by the subsequent plating in the hole, voids were present in the copper through-hole plating of the finished boards. During soldering, molten solder flows into these voids and penetrates into the epoxy-glass base material causing the epoxy to outgas. The outgassing from the epoxy causes the solder joint to bubble and expel small solder balls over the surface of the board. 
The fabrication process for the Lambda printed wiring boards has been changed to prevent degradation of the as-drilled holes in the boards during copper plating. Boards fabricated using a cyanide copper or a sulfate copper process instead of the original fluoborate copper showed no evidence of hole degradation and exhibited no outgassing from the holes. Sulfate copper plating is now being used with good results.

\section{FUTURE WORK}

No further activity is planned for this project. 